ISSN: 2277-3754

ISO 9001:2008 Certified

International Journal of Engineering and Innovative Technology (IJEIT)

Volume 10, Issue 7, January 2021

\title{
Comparative evaluation of Induction Electrodes of Electric Field Sensor based on MEMS
}

\begin{abstract}
There is an urgent need for electric field measurements in such areas as aerospace, power systems, ship rail transit, and lightning monitoring. Due to its advantages of small size, light weight, easy integration and easy mass production, the MEMS Electric field Sensor has become a research hotspot for many academics. Among the published research results, there are three main inductive structure that are feasible and effective, which respectively are single-layer sidewall sensing electrode structure with horizontal vibration, double-layer planner sensing electrode structure with horizontal vibration and aperture-plate sensing electrode structure with vertical vibration. This article comprehensively analyzes and compares the sensing structures of three types of MEMS EFS in terms of induction principles, fabrication feasibility, sensitivity, and lifetime. The simulation results show that single-layer sidewall induction electrode structure with horizontal vibration is the most ideal induction electrode structure.
\end{abstract}

Yaosheng Huang ${ }^{\mathrm{a}}$, Ya Mou ${ }^{\mathrm{b}}$, Zhanqing Yu ${ }^{\mathrm{b}, *}$, Zipan Nie, Chao Zhang ${ }^{\mathrm{a}}$, Zhiming Zhen ${ }^{\mathrm{a}}$, Rong Zeng ${ }^{\mathrm{b}}$

a Jiangmen Power Supply Bureau of Guangdong Power Grid Co, China Southern Power Grid Corporation, China

${ }^{\mathrm{b}}$ State Key Lab of Power Systems, Department of Electrical Engineering, Tsinghua University, China

Keywords: MEMS, electric field sensor, induction electrode.

\section{BACKGROUND AND GOALS}

Lightning [1], volcanoes, earthquake [2] and other natural phenomena occur along with the change of electric field in the surrounding space. Electric field is closely related to the health of animals and plants: strong electric field may induce variation in some genes. Furthermore, strong electric field may damage the insulation of the equipment, causing the equipment to work abnormally.

Manuscript received: 14 December 2020

Manuscript received in revised form: 11 January 2021

Manuscript accepted: 28 January 2021

Manuscript Available online: 15 February 2021
In short, electric field is closely related to the natural phenomena and biological. Therefore, the electric field measurement has an important influence on many aspects of production and life.

Over the past decades, field mills were commonly used to measure electric field for its good performance in stability and linearity [3]. Field mill is mainly composed of rotating shielding electrodes, static sensing electrodes and a motor. But, field mill has drawbacks of large size and causing seriously distortion of electric field. Cylindrical field mill is similar to field mill [3]. The difference between the two EFS is that both sensing electrodes and shielding electrodes of cylindrical field mill rotate periodically. In 1893, CR Frederick found the phenomena that refractive index of the crystal in the electric field changes with the electric field strength changes. After that, a series of EFS based on the bubble phenomenon had been designed, fabricated and measured. Different to previous EFS, this kind of EFS has fast responsibility and can measure the high frequency $\mathrm{AC}$ electric field (up to $\mathrm{GHz}$ ). However, apparatus such as light source, receiver and optical fiber are must in the measurement system, adding complexity to the measuring system. In terms of measuring convenience, it is not as good as cylindrical field mill and shutter-type field fill.

Micro Electromechanical System (MEMS) is mainly composed of three parts of sensor, that are sensor, actuator and micro energy. It has the advantages of miniaturization, intelligence, multi-function, high integration and suitable for mass production [6]. Among the published research results, there are three main inductive structure that are 
ISSN: 2277-3754

ISO 9001:2008 Certified

International Journal of Engineering and Innovative Technology (IJEIT)

Volume 10, Issue 7, January 2021

feasible and effective, which respectively are single-layer sidewall sensing electrode structure with horizontal vibration [7], double-layer planner sensing electrode structure with horizontal vibration [8] and aperture-plate sensing electrode structure with vertical vibration. However, researchers have studied only one or two types of MEMS electric field sensors. No one is quite clear about the performance differences in some aspects of these three structures. In this paper, the advantages and disadvantages of each structure are analyzed in the aspects of principle, induction sensitivity and machining feasibility. By comparison, single-layer sidewall sensing electrode structure with horizontal vibration is the best induction structure.

\section{STRUCTURE AND PRINCIPLE OF THREE}

\section{KINDS OF INDUCTION ELECTRODES}

The typical induction electrode structures of MEMS electric field sensors include three types of single-layer sidewall sensing electrodes with horizontal vibration, double-layer planner sensing electrode structure with horizontal vibration and aperture-plate sensing electrode structure with vertical vibration. Comparison in terms of operation principle, processing technology, lifespan and sensibility will be depicted in detail.

\section{A. Single-layer Sidewall Sensing Electrode \\ Structure with Horizontal Vibration}

As defined in Fig.1, horizontal vibration single-layer sidewall sensing electrodes consist of electrode sensing and electrodes. The induction electrode type is a single stratum, that is, electrodes and protective electrodes that are sensed at the same level and produced relatively easily. Electrodes sensing are grounded and moved horizontally. If the protective electrodes pass around the sensing electrodes, the sensing electrode is protected from the sensing electrodes, and the charge is decreased on the side wall. On the other hand, the load on the sidewall of sensing electrodes increases when the shielding electrodes are far away from the sensing part. By detecting the shift in charges on the sensing components, the intensity of the electric field can be measured. Owing to the fact that gravity does not help to shield the electrode, the strain or stress of the shield electrodes can be restored to zero. Consequently, this horizontal mode has good fatigue resistance efficiency.

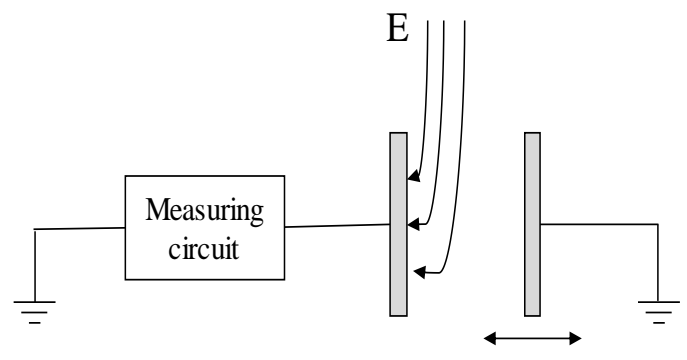

Fig. 1: Diagram of single-layer sidewall sensing electrodes with horizontal vibration

\section{B. Horizontal Vibration Double-Layer planar induction electrode structure}

As shown in Fig. 2, the blinding electrodes and sensing electrodes of the horizontal vibration are divided into two layers by a double-layered planar induction structure. The electrodes are on the top and the electrodes are on the bottom. Like the first type, horizontal vibration of the protective electrodes of this type occurs. The successful zone of sensing electrodes exposed to the electrical field decreases the defensive electrodes that shift left. The charges on the upper surfaces of the sensing electrodes are decreased with the effective surface, in compliance with the electrostatic induction legislation.

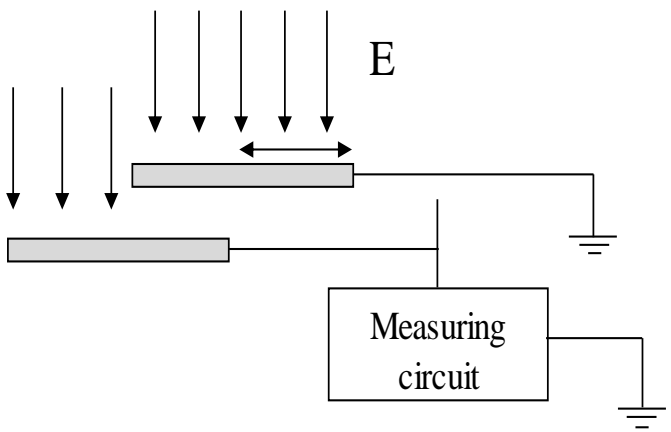

Fig. 2: Diagram of double-layer planner sensing electrode structure with horizontal vibration

Instead, the exposed region to the electric sensing electrodes increases as the shielding electrodes shift right, 
ISSN: 2277-3754

ISO 9001:2008 Certified

International Journal of Engineering and Innovative Technology (IJEIT)

Volume 10, Issue 7, January 2021

which means that the charges inducted also increases. Due to the double-layer structure, there is difficulty in processing. After the sensing electrodes and shielding electrodes are separately manufactured in the process, they are bonded together. The bonding procedure increases the complexity of the process and reduces the rate of final products.

\section{Vertical Vibration Plate Induction Electrode}

Like aforementioned two induction structure, aperture-plate sensing electrode structure with vertical vibration also consists of sensing electrodes and shielding electrodes, and shielding electrodes are directly grounded. Horizontal vibration double-layer planar induction electrode structure and vertical vibration plate induction electrode structure are both double-layer structure. The both two have the disadvantage of production difficulties and low rate of final products. The difference between the two structures is that the former is horizontal vibration and the latter is vertical vibration. In the process of vertical movement of the shielding electrode, gravity makes contribution to the movement. Due to the influence of gravity, the shield electrode will also be subjected to stress in the absence of driving force, thereby affecting the degree of fatigue.
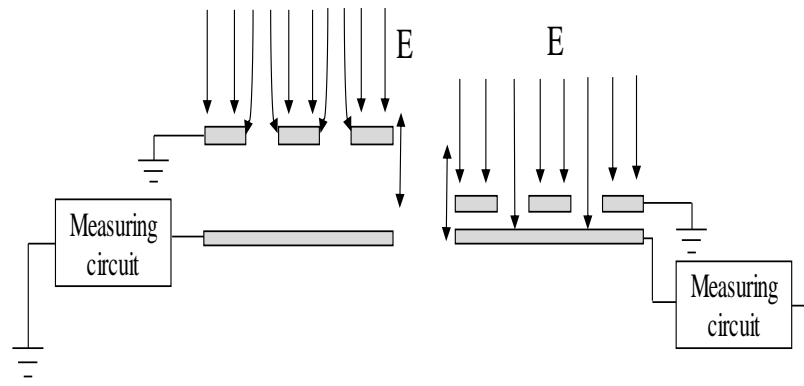

Fig. 3: Diagram of aperture-plate sensing electrode structure with vertical vibration

III. SIMULATION ANALYSIS AND RESULTS

Through the above analysis, the third type induction structure has weak fatigue resistance and short life. Taking factors of device lifetime into account, the third structure is obviously not the best induction electrode structure. In the aspect of processing, the first type induction structure is better than the second one. In this section, a series of simulation based on COMSOL Multi-physics Field have completed to compare the sensitivity of the first two induction structure in this paper. The simulation conditions are listed in the Table.1.

Table 1: Parameters description in simulation

\begin{tabular}{|c|c|c|}
\hline SOI wafer with low resistance & Type 1 & Type 2 \\
\hline Sensing area & $1 \mathrm{~mm}^{2}$ & $1 \mathrm{~mm}^{2}$ \\
\hline $\begin{array}{c}\text { Center distance of two identical } \\
\text { polarity sensing electrodes }\end{array}$ & $40 \mu \mathrm{m}$ & $40 \mu \mathrm{m}$ \\
\hline Distance of two layer & - & $10 \mu \mathrm{m}$ \\
\hline Width of sensing electrodes & $8 \mu \mathrm{m}$ & $15 \mu \mathrm{m}$ \\
\hline Width of shielding electrodes & $8 \mu \mathrm{m}$ & $15 \mu \mathrm{m}$ \\
\hline Length of sensing electrodes & $450 \mu \mathrm{m}$ & $450 \mu \mathrm{m}$ \\
\hline Length of shielding electrodes & $450 \mu \mathrm{m}$ & $450 \mu \mathrm{m}$ \\
\hline Thickness of sensing electrodes & $20 \mu \mathrm{m}$ & $10 \mu \mathrm{m}$ \\
\hline $\begin{array}{c}\text { Thickness of shielding } \\
\text { electrodes }\end{array}$ & $20 \mu \mathrm{m}$ & $10 \mu \mathrm{m}$ \\
\hline $\begin{array}{l}\text { Horizontal center distance } \\
\text { between sensing electrode and } \\
\text { shielding electrode }\end{array}$ & $12 \sim 24 \mu \mathrm{m}$ & $0 \sim 20 \mu \mathrm{m}$ \\
\hline SOI wafer with low resistance & Type 1 & Type 2 \\
\hline $\begin{array}{l}\text { Vertical center distance between } \\
\text { sensing electrode and shielding } \\
\text { electrode }\end{array}$ & -- & $10 \mu \mathrm{m}$ \\
\hline $\begin{array}{l}\text { Number of sensing electrode } \\
\text { groups (each group contains a } \\
\text { positive and negative electrode) }\end{array}$ & 24 & 24 \\
\hline $\begin{array}{c}\text { Background electric field } \\
\text { intensity }\end{array}$ & $15 \mathrm{kV} / \mathrm{m}$ & $15 \mathrm{kV} / \mathrm{m}$ \\
\hline Induced current amplitude /pA & 1383 & 218 \\
\hline
\end{tabular}

In the table one, Type 1 means the single-layer sidewall sensing electrode structure with horizontal vibration, and Type 2 is double-layer planner sensing electrode structure with horizontal vibration.

According to the simulation about induced charge of 
ISSN: 2277-3754

ISO 9001:2008 Certified

International Journal of Engineering and Innovative Technology (IJEIT)

Volume 10, Issue 7, January 2021

different induction electrode structures, the following conclusions are obtained:

(1) The sensing electrodes and shielding electrodes require the same potential. Moreover, the closer the potential of sensing electrodes is to the ground potential, the higher the correctness of the spatial electric field can be reflected.

(2) The MEMS EFS designed by the sidewall shielding method is most suitable structure when the thickness of the sensing electrode is $10 \mu \mathrm{m}$, according to the thickness scan simulation results.

(3) The MEMS EFS designed by the surface shielding method, the shielding electrodes thickness is preferably less than $10 \mu \mathrm{m}$; otherwise the sidewall of the shielding electrodes will play a shielding role, which is harm to the measurement of the electric field intensity.

(4) MEMS shield electrodes designed according to the surface shielding method to design the spacing slightly larger, so that the induction plate of the electric field measurement.

(5) In the same sensing area, induced charges of the first structure of the sensing electrodes is more than the second. Hence, the first induction electrode structure is the best ideal design for the induced output.

\section{REFERENCES}

[1] Montanya, J., Bergas, J., and Hermoso, B., "Electric field measurements at ground level as a basis for lightning hazard warning”, J. Electrostatics, 60(2), PP: 241-246, 2004.

[2] Mikhailov, Y., Mikhailova, G., Kapustina, O., "Electric and electromagnetic processes in the near-Earth atmosphere before earthquakes on Kamchatka. Geomagn”, Aeron, 46 (6), PP: 796-808, 2006.

[3] Yong C., Haiwen Y., Xiao S., "Model, Design, and Testing of Field Mill Sensors for Measuring Electric Fields under High-Voltage Direct-Current Power Lines", IEEE TRANSACTIONS ON INDUSTRIAL ELECTRONICS, 65(1), PP: 608-615, 2018.
[4] Kasimer, H.W., "Yang-Mills fields on cylindrical manifolds and holomorphic bundles", Communications in Mathematical Physics. 179(3), PP: 737-775, 1996.

[5] Cecelja, F., Bordovsky, M., Balachandran, W., "Electro-optic sensor for measurement of DC fields in the presence of space charge", IEEE Transactions on Instrumentation and Measurement. 51 (2), PP: 282-286, 2002.

[6] Andreas, K., Harald, S., Johannes, S., "Distortion-free measurement of electric field strength with a MEMS sensor", Nature electronics. 1(1), PP: 68-73, 2018.

[7] Riehl, P.S. ,Scott .KL. „Muller R.S., “Electrostatic charge and field sensors based on micromechanical resonators", Journal of Micro electromechanical Systems. 12 (5), PP: 577-589, 2003.

[8] Wijeweera, G., Bahreyni, B., Shafai, C., "Micro machined Electric-Field Sensor to Measure AC and DC Fields in Power Systems", IEEE TRANSACTIONS ON POWER DELIVERY. 24, PP: 988-995, 2009. 